\title{
REALIZANDO LA UTOPÍA COMO UN ESFUERZO DOCTRINAL
}

\section{ANNE PETERS ${ }^{1}$}

RESUMEN: Este artículo examina si y cómo la academia jurídica internacional puede lograr el objetivo alcanzado por otras ciencias exitosas, esto es, la acumulación de conocimiento replicable. Se reflexiona sobre las ideologías y políticas que influyen en la actividad jurídico-académica, que no está completamente "libre de valores". Por último, se analiza cómo la práctica y la academia jurídica internacional pueden apoyarse mutuamente.

Palabras clave: Derecho, Política, derecho internacional, doctrina jurídica internacional, práctica jurídica internacional, análisis normativo, Antonio Cassese.

ABSTRACT: This article investigates whether and how international legal scholarship can achieve what successful sciences do, namely to accumulate replicable knowledge. It reflects about ideology and politics which affect legal scholarly activity which is not totally 'value-free'. Finally, the article examines how international legal practice and scholarship can mutually support each other

Key words: Law, Politics, international law, international legal scholarship, international legal practice, normative analysis, Antonio Cassese.

Sumario: I. Introducción; II. El positivismo crítico de Cassese y sus trampas; III. ¿Qué es lo "académico" de la manera de abordar el derecho internacional por los académicos?; IV. La doctrina jurídica internacional y la reforma al derecho; v. La doctrina jurídica internacional y la política; VI. La doctrina jurídica internacional y la práctica; VII. La doctrina jurídica internacional aplicada y fundacional; VIII. La doctrina jurídica internacional multidimensional; Ix. El análisis positivo y normativo; x. Conclusión.

1 Profesora, Dr. iur., LL.M. (Harvard), Codirectora del Instituto Max Planck de Derecho Público Comparado y Derecho Internacional, Heidelberg, Alemania. Traducción de Karla Jones. Correcciones de Beat Streicher. 


\section{INTRODUCCIÓN}

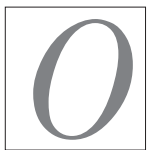

$n$ resiste à l'invasion des armées; on ne résiste pas à l'invasion des idées. ${ }^{2}$ Con esta referencia a Víctor Hugo en su conclusión a "Realizando la Utopía", ${ }^{3}$ Antonio Cassese revela, en términos modernos de las relaciones internacionales, su enfoque "idealista" y parece un hombre que creía en el poder transformativo de las ideas. El mismo Cassese propagó lo que llamó un "positivismo crítico". ${ }^{4}$ Isabel Feichtner, en su trabajo reflexivo, critica este enfoque y termina por negar su calidad como doctrina jurídica. ${ }^{5}$ En este artículo, quiero defender el positivismo "crítico o ideacional” y explicar por qué y cómo puede desarrollarse exitosamente como doctrina jurídica e incluso como "ciencia jurídica", para usar el germanismo de Hans Kelsen.

\section{El positivismo crítico de Cassese y sus trampas}

El positivismo crítico de Cassese es un método para investigar reglas e instituciones con una "adecuada contextualización, tanto socio-política como ideológicamente". ${ }^{6}$ El positivista crítico "debe ser cauteloso de no proyectar sus propias ideologías y prejuicios sociales en sus propuestas de cambio". ${ }^{7}$ Sin embargo, el intérprete

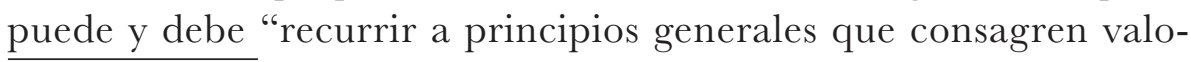

2 Victor Hugo, Histoire d'un crime: Déposition d'un témoin (1887. 2009), p. 639.

3 A. Cassese, Realizing Utopia: The Future of International Law (2012), p. 683. [La traducción al español se realizó por Karla Jones y fue supervisada por la autora. En adelante, para casos similares, se indicará con el texto "la traducción es nuestra"]

4 A. Cassese, Five Masters of International Law: Conversations with R-f Dupuy, $E$ Fiménez de Aréchaga, R Jennings, L Henkin and O Schachter (2011), p. 258.

5 Feichtner, "Realizing Utopia through the Practice of International Law", EfIL, 23 (2012), p. 1143.

6 Cassese, supra nota 4, p. 258.

7 Cassese, supra nota 3, p. 683. 
res universales de la comunidad internacional para llevar a cabo una interpretación teleológica de las normas presentadas". ${ }^{8}$ Dichos principios deberían, por supuesto, también incluir propuestas para la reforma del derecho. Al mismo tiempo, Cassese se dio cuenta que dichos principios generales no proporcionarían una solución al problema analizado. Cuando esos "valores universales resultan estar en conflicto $[. .$.$] el intérprete necesariamente tendrá que apoyarse en$ sus preferencias ideológicas o políticas". ${ }^{9}$

Isabel Feichtner identifica dos críticas: primero, que incluso el positivismo crítico tiene una naturaleza ideológica, es decir, depende de que las preferencias políticas se mantengan ocultas en lugar de ser reveladas, como lo exigía Cassese; en segundo lugar, Feichtner reprueba las limitaciones disciplinarias de la doctrina que Cassese perseguía. Desde su perspectiva, el positivismo crítico es demasiado jurídico pues no incorpora métodos, puntos de vista y argumentos de otras disciplinas. Un abogado internacional debería no únicamente "manifestar sus preferencias ideológicas, sino[...] que debería ir un paso adelante y apoyar sus preferencias al hacer referencia a otras disciplinas, ya sea filosofía moral, economía o teoría social”. Feichtner identifica un dilema: arguye -por las razones expuestas con anterioridad- que es indispensable incorporar puntos de vista y argumentos de otras disciplinas para "ampliar la base de la confrontación de principios". En otras palabras, la interdisciplinariedad es necesaria para mantener la calidad del trabajo académico. Sin embargo, por otro lado, es justamente esta interdisciplinariedad (y la incorporación de otras disciplinas jurídicas, como el derecho privado o el derecho penal en nuestros trabajos) "la que podría reducir nuestro idealismo respecto del derecho (internacional) como instrumento para lograr la Utopía”. Los abogados, si quieren ser verdaderos académicos, no pueden, por lo tanto, ser idealistas. Esto conlleva a Feichtner a la inevi-

\footnotetext{
8 Cassese, supra nota 4, p. 259. [La traducción es nuestra].

9 Ibid., p. 259.
} 
table conclusión: "si como abogados internacionales queremos participar y encontrar consolación en el proyecto utópico del derecho internacional, necesitamos hacerlo no como académicos sino desde la praxis". En pocas palabras, el argumento de Isabel Feichtner es que el tipo de actividad realizada por Antonio Cassese no satisface ni puede satisfacer los requisitos de la academia.

\section{III. ¿QuÉ ES LO "ACADÉMICO" DE LA MANERA DE ABORDAR EL DERECHO INTERNACIONAL POR LOS ACADÉMICOS?}

Esta crítica al intento de Cassese (y de otros) de reconciliar el método académico con un enfoque normativo e idealista ha agregado una perspectiva nueva a los viejos debates sobre el carácter académico (o científico) de la manera de abordar el derecho internacional por parte de la academia jurídica. ¿Realmente esto se merece la etiqueta de "doctrina" (o incluso "ciencia")? Gran parte de la confusión que existe en este punto se remonta a la noción aristotélica de ciencia. Para Aristóteles, la ciencia era posible únicamente en relación con materias necesarias y universales. ${ }^{10}$ Esto se originó de su exigencia de una equivalencia estricta entre el conocimiento y la materia del conocimiento. Desde la perspectiva aristotélica, el derecho pertenecía al campo de la experiencia humana, lo cual se relacionaba con cosas transitorias y perecederas. El conocimien-

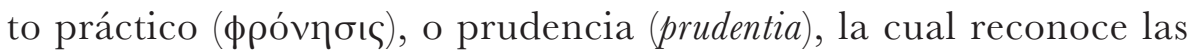
realidades contingentes de la práctica, no era, por lo tanto, ciencia $(\varepsilon \pi ı \tau \eta ́ \mu \eta) .{ }^{11}$ Así, la jurisprudencia era meramente un "sabio conocimiento del Derecho".

10 "Todos concebimos que algo que conocemos científicamente no puede variar[...] un objeto del conocimiento científico, por lo tanto, existe por necesidad. Es, por ende, eterno[...]": Aristóteles, The Nicomachean Ethics, (trad. al inglés H. Rackham, 1996), Libro VI, iii, 2.

11 “[R] esulta que la prudencia no es lo mismo que la ciencia[...] porque los aspectos de la conducta permiten variaciones" ibid., Libro VI, iv, 3). De acuerdo con Harold Berman, la jurisprudencia de Aristóteles no era siquiera $\tau \dot{\chi} \chi \vee \eta$, sino 
Éste no es el lugar para repetir el debate general de si la doctrina

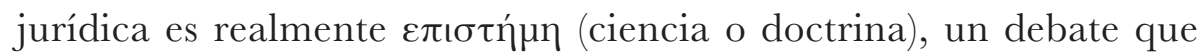
está cargado de cuestiones terminológicas estériles. ${ }^{12}$ En su lugar, simplemente quiero preguntar si y cómo la doctrina jurídica (internacional) logra lo que supuestamente las ciencias deben lograr, es decir, la acumulación de conocimiento intersubjetivo replicable.

Los académicos jurídicos reconocen que la investigación jurídica debería, en principio, producir "nuevos descubrimientos". ${ }^{13}$ Sin embargo, en la doctrina jurídica, las ganancias de conocimiento no son tan obvias e incluso se niega explícitamente que existen. ${ }^{14}$ ¿Cuál es la razón de la carencia de acumulación del conocimiento en la doctrina jurídica? ${ }^{15}$ La razón parece no encontrarse en los métodos de producción del conocimiento. El núcleo del proceso científico es la replicabilidad intersubjetiva del método; es decir,

que le incumbía a la ética, la política, la religión y la retórica. H.J. Berman, Law and Revolution: The Formation of the Western Legal Tradition (1983), p. 133.

12 Vid., v. g., Weinberger, "Der Wissenschaftsbegriff der Rechtswissenschaften", en 5 Studia Leibnitiana, edición especial (Sonderheft) (1975) 102; Kaufmann, "Über die Wissenschaftlichkeit der Rechtswissenschaft", en 72 ARSP (1986) 429; C. ENGEL y W. SchÖn (eds.), Das Proprium der Rechtswissenschaften (2007).

${ }^{13}$ C. f., von Savigny, System des heutigen römischen Rechts, vol. I , (1840), p. xxii (versión en alemán), subrayó que "los conocimientos adquiridos [Kenntnisse] puestos en operación, en comparación con la época anterior, destaca altamente, [...] nada es más enconmiable que el esfuerzo de enriquecer la ciencia con descubrimientos frescos[...]"

14 J.H. von Kirchmann, Die Wertlosigkeit der Jurisprudenz als Wissenschaft (ed. H. H. Meyer-Tscheppe, 1988), p. 13: "[1] a doctrina jurídica[...] ha, desde los tiempos de Bacon, permanecido estática[...] [,] las controversias no han disminuido, sino que han aumentado, e incluso cuando la investigación completa y laboriosa considera finalmente haber alcanzado un resultado estable, pasa una década y la pelea comienza de nuevo".

15 Una razón preliminar podría ser que la doctrina jurídica no busca la verdad (y con ello el conocimiento). Este punto de vista, sin embargo, no le hace justicia a las aspiraciones de la investigación jurídica. 
del camino que lleva al resultado. ${ }^{16}$ En la doctrina jurídica, ante todo, los resultados se obtienen a través del argumento más que a través de la observación empírica. El estándar del argumento en la doctrina jurídica es, obviamente, alto. Los resultados de la doctrina jurídica generalmente serán replicables intersubjetivamente. La razón de la escasa acumulación de conocimiento es, más bien, el enfoque de la investigación jurídica en aplicaciones concretas del derecho. La doctrina jurídica ha sido conducida como "ciencia jurídica aplicada" durante los últimos 100 años. Falta el vínculo que conecta la teoría y los resultados de investigación menos abstractos. Esto es, "más que la construcción de un edificio[...] la acumulación de ladrillos en un montón". ${ }^{17}$

Para construir el edificio de la doctrina jurídica, necesitamos teorías. En la teoría de la ciencia, las teorías se conciben más como modelos o estructuras que como sistemas de declaraciones. ${ }^{18}$ El requisito más general para todas las teorías científicas es el siguiente: las teorías deberían expresar los patrones o estructuras de los datos o de los fenómenos del campo bajo observación, tan mesurada y concisamente como sea posible. Deben reducir la complejidad de manera que "una teoría útil es una compresión de los datos; comprensión es compresión[...] Mientras más simple sea una teoría, mejor se entiende algo". ${ }^{19}$ Es importante que las teorías se interrelacionen como piedras en una casa o piezas de un rompecabezas.

16 De esta manera, la característica central de la ciencia no es ni el uso de las matématicas como pensaba Galileo Galilei, ni el proceso inductivo, como lo sugería Francis Bacon. Vid., H. Schwenke, Zurück zur Wirklichkeit: Bewusstsein und Erkenntnis bei Gustav Teichmüller (2006), pp. 293-297.

17 J. Binder, Philosophie des Rechts (1925), p. 948, refiriéndose al derecho comparado.

18 A. F. Chalmers, What is this Thing called Science? ('Theories as Structures II and II', 104-148) (3a edn, 1999), capítulos 8 y 9.

19 Vid., Chaitin, 'The Limits of Reason', 294(3) Scientific American (Mar. 2006) 74 y las fuentes citadas en ese texto. "Contrariamente, si la única ley que describe datos es en extremo complicada, entonces los datos en realidad no tiene efectos 
Este concepto de teoría es aplicable a la doctrina jurídica. Se reconoce que la mayoría de las llamadas teorías jurídicas no son teorías científicas en el sentido que recién se mencionó. Ejemplos de dichas "no-teorías" en el derecho internacional público incluyen la teoría declarativa del reconocimiento de los Estados contra la teoría constitutiva, la teoría constitucionalista contra la internacionalista respecto del artículo 46 de la Convención de Viena sobre el Derecho de los Tratados, o la teoría absoluta contra la teoría relativa sobre las reservas a tratados multilaterales. Éstas no son teorías, sino simples recomendaciones singulares para solucionar cuestiones jurídicas concretas.

En contraste, existen teorías en el derecho internacional público que sí reducen la complejidad. Un ejemplo de dicha teoría de compresión de datos es la subsidiariedad. La subsidiariedad es la base común de diferentes reglas (por ejemplo, la regla de agotamiento de los recursos internos, la prioridad de las organizaciones regionales sobre las operaciones del mantenimiento de la paz de las Naciones Unidas, y la complementariedad de la Corte Penal Internacional respecto de las cortes nacionales para perseguir crímenes internacionales bajo el artículo 17 de su Estatuto). ${ }^{20}$ Sobre la base de esta reducción de la complejidad, los académicos pueden demostrar que la responsabilidad subsidiaria de la comunidad internacional de garantizar la seguridad humana cuando el Estado territorial falla en su deber de proteger encaja dentro del sistema jurídico internacional. Las teorías jurídicas internacionales en ese sentido ${ }^{21}$ generan conocimiento intersubjetivo replicable y son, por lo tanto, una ciencia exitosa.

jurídicos." Así "una teoría tiene que ser más sencilla que los datos que explica, de otra manera, no explicaría nada" (ibid.). En este punto, Chaitin se apoya en Leibniz: "Mais quand une règle est fort composée, ça qui luy est conforme, passe pour irrégulier”: G.W. LeIBniz, Discours de Métaphysique (2a ed., 1985), p. 14.

20 Cfr. Carozza, "Subsidiarity as a Structural Principle of Human Rights Law", en 97 AfIL (2003), p. 38.

21 Vid., sobre un sentido distinto de la investigación "teórica", es decir, en el sentido de teorías sobre el derecho infra, sección VIII 1. 
IV. LA DOCTRINA JURÍDICA INTERNACIONAL Y LA REFORMA AL DERECHO

Para Antonio Cassese, el académico jurídico internacional debería actuar como un reformador. Él opinaba, "[P] ara que un abogado no sea meramente un técnico, sino alguien con una mentalidad más abierta, también sería importante tratar de contribuir a cambiar el derecho además de interpretar el que ya existe". ${ }^{22}$ Es, según Cassese, "la obligación moral de los abogados proponer reformas de las reglas y regulaciones cuando sea necesario". ${ }^{23}$ Esta sección discute cómo puede explicarse la contribución doctrinal a la reforma del derecho y cómo ésta puede justificarse en términos normativos.

El artículo 38(1) (d) del Estatuto de la Corte Internacional de Justicia menciona "las doctrinas de los publicistas de mayor competencia de las distintas naciones, como medio auxiliar para la determinación de las reglas de derecho". Los términos del artículo 38 (que datan de 1922) manifiestan el Zeitgeist de principios del siglo XX. La referencia a las doctrinas de los publicistas está inspirada en la histórica escuela jurídica y su actitud benévola hacia el derecho de los juristas o el derecho erudito, y fue heredero de la reacción (romántica) contra el ideal codificatorio del renacimiento. La formulación del derecho por los académicos es típica para áreas jóvenes y poco desarrolladas de éste (tal como, en el siglo XIX, el derecho privado doméstico en los Estados europeos continentales, y en el siglo XXI, el derecho privado europeo). Cualquier área nueva, rudimentaria y poco codificada del derecho requiere de estándares académicos. Referirse a Hugo Grocio como el "padre del derecho internacional" justamente señala la labor fundacional de los académicos. Con más esfuerzos de codificación y concretización del orden jurídico, esta contribución necesariamente emigra a un segundo plano.

\footnotetext{
22 CAssese, supra nota 4, p. 143.

23 Ibid., p. 256.
} 
Sin embargo, la importancia del trabajo académico permanece, y puede ser explicada al señalar algunas características especiales del derecho internacional. Éstas son, notablemente, su alto grado de dinamismo y la carencia de órganos legislativos. Por lo tanto, como lo establece, por ejemplo, Johann Caspar Bluntschli, corresponde a los académicos "pronunciar [el Derecho] nuevamente, [...] y a través de este pronunciamiento, aumentar su reconocimiento y validez". ${ }^{24}$ De este modo, Bluntschli les otorgó una función indirectamente legislativa a los académicos. Al hablar y escribir sobre una práctica amorfa y opinio juris, los académicos llevan a cabo una tarea de verbalizar y ordenar, misma que es necesaria para comprender una norma internacional y para hacer que ésta, en primer término, sea operativa. De hecho, parece como si las especiales dificultades de identificación de las normas internacionales hacen crucial el papel de clarificación de los académicos jurídicos internacionales. Y debido a que la identificación conlleva un tipo de sistematización, todos los académicos jurídicos internacionales son, en ese sentido, legisladores. Como lo estableció el ex asesor del gobierno británico, Michael Wood:

[...] una función más amplia e importante de los académicos (quienes frecuentemente también son practicantes) para dar forma y ordenar las hebras dispares que forman al derecho internacional. Más que en cualquier área del Derecho, el derecho internacional le debe su estructura y en muchas ocasiones la aclaración de sus reglas a los

24 J.C. Bluntschli, Das moderne Völkerrecht der civilisirten Staaten als Rechtsbuch dargestellt (1878), prólogo ('Vorwort'), pp. iv-v: "Die Rechtswissenschaft darf [...] meines Erachtens nicht bloss die schon in frühern Zeiten zur Geltung gelangten Rechtssätze protokolliren, sondern soll auch die in der Gegenwart wirksame Rechtsüberzeugung neu aussprechen und durch diese Aussprache ihr Anerkennung und Geltung verschaffen helfen. Je empfindlicher der Mangel gesetzgeberischer Organe ist, welche für die Fortbildung des Völkerrechts sorgen, um so weniger darf sich die Wissenschaft dieser Aufgabe entziehen. Freilich muss sie sich auch davor hüten, der Zukunft vorzugreifen. Sie darf nicht unreife Ideen als wirkliche Rechtssätze und selbst dann nicht verkünden, wenn sie ihre Verwirklichung in der Zukunft klar vorhersieht" (énfasis añadido). 
académicos, $[\ldots]$ En ese sentido son fundamentales para el sistema jurídico internacional. ${ }^{25}$

De cualquier forma, los textos académicos no son derecho. Es un lugar común que estas "obras escritas no son una fuente (formal) del derecho, pero pueden constituir evidencia del mismo". ${ }^{26}$ Los académicos "deben esclarecer qué reglas deben ser aplicadas por la Corte, mas no crearlas". ${ }^{27}$ El artículo 38(1) (d) es la "bodega de donde pueden extraerse las reglas de los párrafos (a), (b), y (c)" ${ }^{28} \mathrm{La}$ explicación clásica de la carencia del poder de legislar de la doctrina jurídica, es que los académicos no son parte de la estructura soberana del Estado. Hace 350 años, Tomás Hobbes expresó este hecho de la siguiente manera: "[1] a autoridad de los doctrinarios, sin la Autoridad del Commonwealth, no hace de sus opiniones derecho, y nunca será así[...] Pues mientras que es naturalmente razonable; es el Poder Soberano el que es derecho". ${ }^{29}$ Y la Corte Inglesa de Almirantazgo determinó en 1778 que

$[\mathrm{u}] \mathrm{n}$ hombre pedante dicta el derecho de las naciones en su clóset;; todo el mundo lo cita, pero a nadie le importa. El uso es sencillamente tan arbitrario como incierto; ¿y quién debe decidir cuando los doctos no están de acuerdo? Bynkershoek, tal como es natural para cualquier escritor $u$ orador que sigue tras otro, disfruta contradecir a Grocio. ${ }^{30}$

25 Wood, "Teachings of the Most Highly Qualified Publicists (Art. 38(1) ICJ Statute)", en R. Wolfrum (ed.), Max Planck Encyclopedia of Public International Law (2011), disponible en: <www.mpepil.com>, párr. 3. [La traducción es nuestra].

26 Ibid., párr. 17.

27 Pellet, "Article 38", en A. Zimmermann, C. Tomuschat, y K. Oellers-Frahm (eds.), The Statute of the International Court of Fustice (2a ed., 2012), párr. 304.

28 S. Rosenne con la asistencia de Y. Ronen, The Law and Practice of the International Court of Fustice, 1920-2005 (4 ${ }^{\mathrm{a}}$ ed., 2006), iii, p. 1551.

29 T. Hobbes, Leviathan (1943 (Orig. 1651)), cap. 26, p. 143. [La traducción es nuestra].

зо The "Renard", 9. Dec. 1778, 165 ER 51, 222, p. 224. 
Sin embargo, deducir la autoridad de los oradores y por ende la validez de las normas internacionales de la soberanía del Estado, no se corresponde con el entendimiento actual de la noción de soberanía, la cual, como se considera hoy en día, no es una fuente autónoma de autoridad, sino que es instrumental para la realización de los objetivos humanos.

La segunda explicación típica de la carencia de la doctrina jurídica del poder de legislar no es mejor. Se trata de la afirmación de que los textos académicos no son una fuente reconocida del derecho internacional. ${ }^{31}$ Sin embargo, la clausura normativa del orden jurídico internacional mediante la inminente construcción de fuentes ha resultado poco útil y es, desde la perspectiva de la teoría jurídica, altamente cuestionable. Parece más provechoso determinar la calidad "de derecho" de cualquier norma social, no mediante la metáfora paradójica de las fuentes, sino desde una base casuística. ${ }^{32}$ Desde esta perspectiva, que se desprende del pluralismo jurídico, la facultad de los actores sociales de hacer derecho no se niega categóricamente. ${ }^{33}$ Consecuentemente, un "derecho erudito moderno" es concebible.

Una alternativa que da cabida a la facultad académica de hacer derecho es expuesta por los estudiosos críticos (critical legal studies) que combinan erróneamente la observación del derecho con su creación. Cuando Martti Koskenniemi establece que "[e]l derecho internacional es una práctica argumentativa", ${ }^{34}$ no establece quién elabora los argumentos ni los argumentos de quién pueden consi-

31 En alemán, no una Rechtsquelle, sino meramente una Rechtserkenntnisquelle: Hillgruber, 'Braucht das Völkerrecht eine Völkerrechtstheorie?', en M. JestaedT y O. LePsius (eds.), Rechtswissenschaftstheorie (2008), pp. 113, 115.

32 T. Vesting, Rechtstheorie (2007), pp. 78-95.

33 Cfr. A. Peters, L. Köchlin, T. Förster, y G.F. Zinkernagel (eds.), Non-state Actors as Standard Setters (2009).

34 Koskenniemi, "Methodology of International Law", en Wolfrum (ed.), supra nota 25, párr. 1 . 
derarse juris-generativos. El entendimiento del derecho internacional como una práctica argumentativa implica que el discurso de la academia es derecho internacional y no es únicamente hablar del derecho internacional. Sin embargo, este enfoque es riesgoso. El discurso académico no constituye derecho como tal. Lo que le da el estatus de derecho internacional a algunos textos no es el hecho de haber sido promulgados por un soberano ni de estar definidos como fuente. Se debe a la doble característica de algunas normas, ellas son socialmente necesarias para la regulación global y han sido elaboradas con la participación de las personas afectadas. Si tomamos esto como estándar, los académicos, como individuos o como comunidad epistémica, ${ }^{35}$ no están autorizados para hacer derecho. Su experiencia no es una base suficiente para crear derecho internacional. Al referirse a un "código" de expertos, la entonces Corte de Primera Instancia formuló los lineamientos relativos a las responsabilidades políticas y la legitimidad democrática de la Comisión y estableció que

Mientras que el ejercicio del poder público por la Comisión está legitimado por el control político del Parlamento Europeo, conforme al artículo 155 del Tratado CE (actualmente artículo $211 \mathrm{CE}$ ), los miembros del SCAN, pese a disponer de una legitimidad científica, no tienen ni legitimidad democrática ni responsabilidad política. Ahora bien, la legitimidad científica no basta para justificar el ejercicio del poder público. [Actualmente artículo 17(1) del TUE (Lisboa), ex artículo 211 de la CE]. ${ }^{36}$

Mientras que la experiencia puede ser una fuente de legitimidad y autoridad, deben agregársele factores adicionales para garantizar

35 De acuerdo con Peter M. Haas, EpComs son "redes de expertos con conocimientos": HAAs, "Introduction: Epistemic Communities and International Policy Co-ordination", en 46 Int'l Org (1992) 1, p. 2.

36 Asunto T-13/99, Pfizer Animal Health v. Consejo de la Unión Europea, Sentencia del Tribunal de Primera Instancia de 11 de septiembre de 2002, G 289/41, párr. 201 . 
que cuenta con autoridad para hacer derecho; es decir, factores institucionales y procesales como la representatividad, la participación y la publicidad. Los académicos jurídicos internacionales no son electos y no representan intereses. Debido a que no intentan regular sus propios asuntos (como los pueblos indígenas, las comunidades religiosas o los comerciantes globalmente activos), sus textos no se comparan al derecho indígena o canónico o a la lex mercatoria.

Para concluir, los académicos jurídicos internacionales, aun cuando actúan en grupos institucionalizados como el Institut de droit international o la International Law Association, no pueden y no deben hacer derecho internacional en el mismo sentido que los gobiernos. Las codificaciones académicas pueden adquirir el estatus de derecho únicamente mediante su adopción por parte de un actor gubernamental o inter-gubernamental. Un ejemplo es el Código Lieber, el cual se convirtió en una instrucción formal para el Ejército solo después de su incorporación a una orden ministerial promulgada por el Secretario de la Defensa. ${ }^{37}$

Nuevamente, la razón de la necesidad de dicha ratificación no es que los académicos no sean parte de la estructura soberana del Estado o que sus textos no sean definidos como fuente, sino que las instituciones y procedimientos en las que realizan códigos, resoluciones y memoranda carecen en gran medida de los factores legitimadores de representatividad, participación, publicidad y rendición de cuentas. En consecuencia, la autoridad de los académicos no es institucional, procesal o social, sino únicamente epistémica.

Y esta situación, para subrayar un punto importante, no puede ser modificada sin que la academia pierda su esencia. Los académicos no rinden ni deben rendir cuentas a clientes reales, sino únicamente

37 "Lieber Code", Instructions for the Government of Armies of the United States in the Field, 24 de abril de 1863. Las normas fueron revisadas por un grupo de miembros del Ejército y luego adoptadas por el entonces Secretario de la Defensa, Ed Townsend, Ayudante General Auxiliar (Órdenes del General No. 100), disponibles en: <http://civilwar.home.com/liebercode.htm>. 
a entes ideales como la comunidad científica, la verdad, el público, sin que esta rendición de cuentas ideacional esté formalizada. Justamente esta falta de rendición de cuentas es la contraparte de la falta de poder de los académicos para "hacer derecho". Ello, en su turno, es una precondición para pensar libremente y fuera de lo convencional. Únicamente debido a que los textos académicos no tienen consecuencias jurídicas directas (como derecho), y solo porque los académicos carecen de responsabilidades formales e institucionales (lo cual no excluye una responsabilidad más amplia frente a la sociedad en su conjunto), es la razón por la cual pueden dedicarse a concebir experimentos y a la especulación, y por lo tanto "proveer de ideas y sacar propuestas a flote que podrían fungir como 'parteras' del cambio jurídico y social", tal como dijo el constante ingeniero social Cassese. ${ }^{38}$

\section{LA DOCTRINA JURÍDICA INTERNACIONAL Y LA POLÍTICA}

La obra de Antonio Cassese es profundamente política. Desmiente la búsqueda pura de la separación estricta entre el derecho (y la doctrina jurídica) y la política, como lo formuló enérgicamente Hans Kelsen. En el prólogo de Kelsen a su comentario de la Carta de la Organización de las Naciones Unidas de 1950, así como en su obra Principios de Derecho Internacional Público de 1952, subrayó que estas obras contenían un "enfoque jurídico y no político" de la Organización de las Naciones Unidas y otros aspectos internacionales. Kelsen continuó al expresar que el libro "se ocupa del derecho de la Organización, y no así de su papel actual o deseado en el juego internacional de poderes. Es posible la separación del derecho y la política en la presentación de problemas nacionales o internacionales". ${ }^{39}$

38 CAssese, supra nota 3, p. 683. [La traducción es nuestra].

39 H. Kelsen, The Law of the United Nations (1950), p. viii. Vid., Kelsen, 'Preface to the First Edition (1952)', en H. Kelsen y R.W. Tucker (eds.), Principles of International Law ( $2^{\mathrm{a}}$ ed., 1967), p. ix: "Creo que es necesario enfatizar el carácter 
En contraste con la creencia y la aspiración de Kelsen, hoy en día es ampliamente reconocido que los académicos jurídicos internacionales son actores políticos. Primero, porque su objeto de estudio es en sí mismo un asunto político. El derecho internacional es altamente político. Los realistas estrictos como Georg Schwarzenberger lo llaman "poder disfrazado". ${ }^{40}$ En contraste, el idealista realista Antonio Cassese (al citar a Georges Scelle) caracterizó al derecho jurídico internacional (desde mi punto de vista de manera más adecuada), como el "resultado de la combinación de la ética y el poder". ${ }^{41}$

El derecho internacional es político, no solo porque depende del poder político, sino también porque transporta valores políticos. Las escuelas de pensamiento más influyentes de nuestro tiempo, la escuela New Haven ${ }^{42}$ y los estudios académicos críticos (Critical Legal Studies), han insistido en este punto, aunque con argumentos distin-

puramente jurídico de este libro, en oposición con la tendencia generalizada entre los autores del derecho internacional, quienes - a pesar de que no se atreven a negar el carácter jurídico y por lo tanto la fuerza vinculante de este orden social-abogan por un enfoque distinto al jurídico, es decir, el político, como el enfoque adecuado. Este punto de vista, en mi opinión no es más que un intento de justificar la no aplicación del derecho existente en caso de que esté en conflicto con algún interés, o más bien, con lo que el autor respectivo considera el interés de su Estado". Todo lo demás "no era una teoría política del derecho internacional, sino una ideología política" (énfasis añadido). [La traducción es nuestra].

40 G. Schwarzenberger, Power Politics: A Study of World Society (3a ed., 1964), pp. 199 y 202-203: "la función principal del derecho es asistir en el mantenimiento de la supremacía de la fuerza y las jerarquías establecidas con base en el poder[...] las políticas del poder disfrazadas". [La traducción es nuestra].

${ }^{41}$ Cassese, supra nota 3, p. 683; G. Scelle, Manuel de droit international public (1948), p. 6: "Les règles de droit viennent de la conjonction de l'éthique et du pouvoir". [La traducción es nuestra].

42 Cfr. R. Higgins, Problems and Process: International Law and How We Use it (1994), p. vi: "Intento demostrar que existe una elección inescapable que debe hacerse entre la percepción del derecho internacional como un sistema de reglas neutrales y el derecho internacional como un sistema de toma de decisiones para conseguir ciertos valores declarados". [La traducción es nuestra]. 
tos, y no se han cansado de revelar, mediante nuevos ejemplos, las pretensiones de neutralidad y tecnicismo del derecho internacional como una quimera.

En segundo lugar, los académicos jurídicos son políticos puesto que son expertos. Los expertos no son técnicos, neutrales, ni sin ideología, es decir, apolíticos. Por el contrario, lo que ocurre es la "política de la experticia". ${ }^{43}$ "[P] ues el conocimiento es en sí mismo poder", como lo planteó Francis Bacon. ${ }^{44}$ Michel Foucault le dio un giro diferente a este punto de vista: los objetivos del conocimiento y los objetivos del poder son los mismos "en el conocimiento controlamos, y al controlar conocemos". ${ }^{45}$

Finalmente, el investigador en derecho internacional es un actor político pues sus juicios de valor normalmente conllevan implicaciones políticas. Los valores son un componente de cualquier elaboración académica del derecho internacional. El Werturteilsstreit ${ }^{46}$

43 Kennedy, "The Politics of the Invisible College: International Governance and the Politics of Expertise", en 5 European Human Rts L Rev (2001) 463; id., "Challenging Expert Rule: The Politics of Global Governance", en 5 Sydney L Rev (2005) 3 .

44 Francis Bacon, Mediationes Sacrae (1597), cap. 11, 'Of Heresies', p. M4 (Con respecto a Dios).

45 Stanford Encyclopedia of Philosophy, 'Michel Foucault' (2008). M. Foucault, Discipline and Punish (trad. A. Sheridan, 1975), pp. 170-177. Foucault analizó la co-constitución mutual del conocimiento y del poder en relación con la observación (visual) en las prisiones como método de ejercer un poder "disciplinario", pero sus textos sobre este punto han sido recibidos más como una apreciación general por la doctrina jurídica posterior (notablemente la doctrina jurídica crítica).

46 De acuerdo con Max Weber, "la jurisprudencia[...] evalúa lo que es válido de conformidad con las reglas del pensamiento jurídico, el cual está compuesto en parte por la lógica y en parte por los esquemas establecidos convencionalmente. Así, determina si ciertas reglas jurídicas y ciertos modos de interpretación deben considerarse vinculantes. No responde la pregunta precisamente de si estas reglas deben ser creadas. La jurisprudencia sólo puede declarar que, si uno quiere triunfar, entonces esta norma jurídica es la manera correcta de hacerlo de conformidad con las normas de nuestro sistema jurídico": WEBER, Wissenschaft als Beruf, (1919), p. 23 (énfasis en el original). 
y el Positivismusstreit ${ }^{47}$ han eliminado la antigua creencia reconocida de que la ciencia y los valores podían separarse. Anteriormente, la única pregunta que se planteaba era si el académico debía o no pronunciar algún juicio de valor. Más allá del Positivismusstreit, la problemática es vista al revés: la severidad de la ciencia y de los valores ha sido cuestionada. La pregunta dejó de ser si el académico debía o no pronunciar un juicio de valor, sino que por el contrario, si en efecto podía abstenerse de hacerlo. La respuesta común de hoy en día, y la de Isabel Feichtner, ${ }^{48}$ es que no. Una actividad académica completamente libre de valores parece imposible, pues cualquier pronunciamiento e interpretación están pre-estructurados por el Vorverständnis del orador. La doctrina jurídica internacional es libre de valores únicamente en el sentido de que (como se explicó previamente) no genera las normas (jurídicas), sino únicamente produce pronunciamientos sobre las normas (sobre el derecho).

Por otro lado, dotar de expresión a las convicciones subjetivas no es el propósito principal de la doctrina. Los académicos jurídicos internacionales deben, por lo tanto, encontrar un justo equilibrio entre el postulado poco realista de la libertad de valores (Wertfreiheit) y una evaluación y una sobre evaluación de los mismos. ${ }^{49}$ Max Weber escribió que cuando estos valores se exponen y se reflejan, mas no se venden como ideas científicas, la dependencia de tales valores no daña el carácter académico de la reflexión. ${ }^{50}$ En el mismo sentido, Antonio Cassese expresa: "[l] o que importa[...] es que él o ella [el/ la académico/a] debe referir explícita y claramente que la elección

47 Vid., H. Maus y F. Fürstenberg (eds.), Der Positivismusstreit in der deutschen Soziologie (1969).

48 Feichtner, nota 5, passim.

49 Engi, "Wissenschaft und Werturteil - Wissenschaft und Politik", en 4 Ancilla iuris (2009) 25.

50 WeBER, "Die Objektivität sozialwissenschaftlicher und sozialpolitischer Erkenntnis", (1904), en ibid., Methodologische Schriften, ed. por Johannes Winckelmann (1968), pp. 1, (p. 4). 
entre dos valores en conflicto está basada en una inclinación o sesgo personal, y no en una precedencia jurídica 'objetiva' de un valor sobre el otro". ${ }^{51}$

En este sentido, toda la actividad académica es inexorablemente política. En 2004, durante la conferencia inaugural de la European Society of International Law, en Florencia, Martti Koskenniemi expresó: "[1] a elección no es entre derecho y política, sino entre una política del derecho y la otra. Todo está en juego, pero no para todos. ¿Y cómo se puede distinguir? Pues, en la misma manera en la que distinguimos entre lo que es y lo que no es kitsch". ${ }^{52}$

\section{LA DOCTRINA JURÍDICA INTERNACIONAL Y LA PRÁCTICA}

Antonio Cassese era un académico brillante, un homme de lettre, pero también un practicante internacional muy activo y reconocido.

\section{Cómo LA PRÁCTICA APOYa a LA ACADEMIA}

Para Cassese era "obvio decir que uno no puede ser un buen abogado sin tener, en algún punto u otro, práctica en el derecho". ${ }^{53}$ En primer lugar, la práctica jurídica internacional (y la práctica de uno mismo) provee, de hecho, temas para el análisis académico. ${ }^{54}$ En segundo lugar, la experiencia práctica propia ayuda a dilucidar dónde se encuentra verdaderamente el derecho internacional empíricamente. Por ejemplo, un profesor que explica el derecho a sus alumnos, puede corroborar que sus afirmaciones reflejan el derecho

51 Cassese, supra nota 4, p. 259. [La traducción es nuestra].

52 Koskenniemi, "International Law in Europe: Between Tradition and Renewal", en 16 EfIL (2005) 113, p. 123.

53 Cassese, supra nota 4, p. 260. [La traducción es nuestra].

54 Vid., sobre el papel de los practicantes y los doctrinarios en el derecho internacional de manera más general Peters, "Rollen von Rechtsdenkern und Praktikern - aus völkerrechtlicher Sicht", en Berichte der deutschen Gesellschaft für Völkerrecht 47 (Heidelberg: CF Müller 2012), pp. 105-173. 
tal como es, si se pregunta si dichas explicaciones se mantendrían también ante la CIJ.

En tercer lugar, la práctica permite probar las teorías (académicas) propias. Siendo presidente de la CIJ, Lord McNair estableció que:

Si puedo expresar mi testimonio tanto como profesor como practicante, puedo decir que constantemente he tenido la siguiente experiencia. Mientras que pude haber pensado, como profesor o como el autor de un libro o artículo, que había examinado adecuadamente una norma jurídica en particular, constantemente he encontrado, que cuando me he enfrentado a la misma norma jurídica al escribir una opinión profesional o al contribuir a una sentencia, me ha sorprendido la apariencia distinta que la norma puede asumir cuando está siendo examinada para su aplicación práctica a ciertos hechos alegados. Tal como se establece en el libro, puede parecer el más perfecto ejemplo de sabiduría, pero cuando quiere aplicarse, sus calificaciones y modificaciones necesarias surgen en la mente. De ninguna manera estoy sugiriendo que el enfoque académico es más superficial que el práctico[...] [E]n mi opinión, cuando el abogado y el juez se enfrentan con la necesidad de aplicar una norma jurídica, o una supuesta norma jurídica a ciertos hechos establecidos por la evidencia, es probable que el elemento jurídico presente en la solución que resulte será una norma jurídica más útil y más práctica que una norma elaborada por un profesor o autor en su estudio mientras trabaja solo y en abstracto. ${ }^{55}$

En conclusión, la práctica jurídica proporciona la "comprobación de la realidad” de la doctrina jurídica internacional.

55 Lord MaNaIR, "The Development of International Justice: Two Lectures Delivered in the Law Centre of New York University" (1954), en Lord MaNAIR, Selected Papers and Bibliography (ed. Sir Gerald Fitzmaurice und R.Y. Jennings, 1974), pp. 242, 257-258. [La traducción es nuestra]. 
Mientras que la práctica jurídica internacional evidentemente es útil e importante para el académico, la fórmula invertida es igualmente verdadera: la doctrina internacional puede ayudar a la práctica jurídica internacional. ¿Bajo qué circunstancias y de qué manera ocurre lo anterior?

Hans Georg Gadamer escribió que "la teoría debe justificarse ante los foros prácticos". ${ }^{56}$ Así que ¿la teoría sólo es valiosa si tiene aplicación práctica? Alego que el poder explicativo de una teoría ya es en sí mismo una forma de aplicación práctica: no hay nada más práctico que una buena teoría. ${ }^{57}$

El vínculo de la doctrina jurídica con la práctica ha sido tradicionalmente estrecho. En Europa continental, la doctrina jurídica ha sido llamada "una teoría para reflejar la práctica", cuya esencia es ésa relevancia práctica. ${ }^{58}$ Bajo esta perspectiva, la doctrina jurídica

56 Gadamer, "Lob der Theorie", en H.-G. Gadamer, Lob der Theorie: Reden und Aufsätze (1983), pp. 26, 38.

57 Este dictum es atribuido a Immanuel Kant pero probablemente fue acuñado por Ludwig Boltzmann. Vid., Peters, "There is Nothing More Practical than a Good Theory: An Overview of Contemporary Approaches to International Law", en 44 German Frbk Int'l L (2001) 25. Kant, "Über den Gemeinspruch: Das mag in der Theorie richtig sein, taugt aber nichts in der Praxis", en W. Weischedel (ed.), Immanuel Kant: Werke in 12 Bänden, xi (1977), pp. 127-172, Cap. III, "Vom Verhältnis der Theorie zur Praxis im Völkerrecht, in allgemein-philantropischer Absicht, d.i. kosmopolitischer Absicht betrachtet". Esto fue expresado por primera vez (sin referencia a Kant) por Boltzmann, "Über die Bedeutung von Theorien (1890)", en L. Bolzmann, Populäre Schriften (ed. E. Bora, 1979), pp. 54, 57: "Daß [...] die Theorie auch das denkbar praktischste, gewissermaßen die Quintessenz der Praxis sei”.

58 Von Arnauld, "Die Wissenschaft vom öffentlichen Recht nach einer Öffnung für die sozialwissenschaftliche Theorie", en A. Funke y J. Lüdemann (eds), Öffentliches Recht und Wissenschaftstheorie (2009), pp. 65, 75 y nota. 52; Schulze-Fielitz, "Staatsrechtslehre als Wissenschaft: Dimensionen einer nur scheinbar akademischen Fragestellung", en H. Schulze-Fielitz (ed.), Staatsrechtslehre als Wissenschaft (2007), pp. 11, 26. 
es de alguna manera peculiar una ciencia aplicada en lugar de una ciencia fundacional (vid., sobre esto la sección VII, infra).

Por el contrario, en EEUU, la doctrina jurídica parece haberse separado de la práctica jurídica, y particularmente, de la práctica judicial. Los textos académicos parecen ser muy teóricos en el sentido del "Derecho y...", que parecen irrelevantes y poco interesantes para la práctica jurídica y, en consecuencia, no son citados por los tribunales. Un observador ha caracterizado la situación como alejamiento, indiferencia mutua, poca conexión y una "brecha entre la academia y la profesión". ${ }^{59}$ John B. Bellinger III, consultor jurídico del Departamento de Estado de EEUU desde 2005 hasta 2009, alentó a las revistas jurídicas norteamericanas dirigidas por estudiantes "a tratar de apartarse de lo teórico, que generalmente no es útil para los abogados practicantes del gobierno[...] encontré que el 90\% de los artículos de estas revistas no son realmente útiles porque son muy académicos". ${ }^{60}$

Alego que mientras que la situación de alienación existente en EEUU es infértil, el fetichismo de la Europa continental con la práctica también lo es. En las secciones siguientes, abogo por una vía media en tres niveles: Primero, la investigación jurídica aplicada debe ser complementada por investigación fundacional. Segundo, el análisis doctrinal se debe complementar con investigación empí-

59 Twining, Farnsworth, Vogenauer y Tesón, "The Role of Academics in the Legal System", en P. Cane y M. Tushnet (eds), The Oxford Handbook of Legal Studies (2003), pp. 920, 929-933.

60 Bellinger y sus colegas están interesados en artículos que brinden un panorama, es decir, sobre negociaciones de tratados, especialmente de los antiguos, y con información sobre Estados extranjeros. Por lo menos "ocasionalmente encontraríamos personas que realmente pensaban una cuestión y que nos proporcionarían algo que no hubiéramos pensado antes. Así, creo que el trabajo realizado por las revistas de derecho internacional es muy útil siempre y cuando no se vuelva muy académico": Bellinger III, 'Interview', 52 Harvard Int'l LJ - online (2010) 32, p. 33. [La traducción es nuestra]. 
rica, ética y teórica. Tercero, el análisis positivo debe ser complementado por el análisis normativo.

VII. LA DOCTRINA JURÍdICA INTERNACIONAL APLICADA Y FUNDACIONAL

Con el riesgo de establecer lo obvio, debe señalarse que la doctrina jurídica internacional fundacional es indispensable. Esa búsqueda se ocupa de la dicotomía ideal-típica entre ciencia aplicada y ciencia fundacional. La doctrina jurídica internacional aplicada genera conocimiento a un nivel bajo de abstracción, mismo que puede ser directamente utilizado para resolver problemas jurídicos concretos. Los estudios orientados a la aplicación brindan asesoría a instituciones y titulares de oficinas, y les ofrecen ayuda concreta en la toma de decisiones o en la preparación de acuerdos internacionales. La línea entre este tipo de investigación y la práctica jurídica internacional es borrosa. La doctrina "fundacional", en contraste, proporciona conocimiento sobre estructuras, desarrollos o patrones básicos del derecho internacional. Un ejemplo son los diseños doctrinarios del constitucionalismo global y del derecho administrativo global.

Únicamente este tipo de investigación puede soportar la dinámica extrema del desarrollo jurídico internacional, particularmente en algunos campos como el derecho penal internacional o el derecho de la inversión extranjera. Los académicos jurídicos internacionales deben reaccionar trabajando en un nivel suficiente de abstracción y de generalidad. Solamente entonces, su trabajo será independiente de los últimos cambios técnicos y podrá referirse a un objeto de estudio duradero.

Únicamente de este modo los académicos pueden escapar del destino expresado por el Procurador prusiano Julius Hermann von Kirchmann en su famosa clase de 1847 en Berlín sobre la Inutilidad de la Jurisprudencia como Ciencia. Kirchmann había identificado la transitoriedad de la materia del derecho como "el malestar fun- 
damental del que la ciencia sufría". "Al hacer de lo accidental su objeto, se vuelve fortuito en sí mismo, tres palabras correctivas del legislador, y bibliotecas jurídicas enteras se vuelven papel para triturar." ${ }^{61}$ La manera de no producir papel para triturar es emplear cuestiones jurídicas fundacionales.

VIII. LA DOCTRINA JURÍDICA INTERNACIONAL MULTIDIMENSIONAL

La actividad de los académicos jurídicos internacionales será exitosa, es decir, generará conocimiento que puede ser transmitido de una manera intersubjetiva, cuando sea conducido en múltiples dimensiones. ${ }^{62}$

\section{DOCTRINAL}

En primer lugar, alguna parte de la actividad debe ser doctrinal. La academia doctrinal esboza la estructura del derecho internacional público. Primero, lleva a cabo una visión del derecho tal como está al organizar conceptos jurídicos, principios básicos y reglas para la toma de decisiones. Segundo, ordena y estructura el derecho. A esta dimensión de la investigación se le denomina doctrinal porque está atada a normas jurídicas, principios y decisiones que se consideran como doctrinas o incluso dogmas. El método de la investigación doctrinal es sobre todo el análisis semántico lógico. Un académico puede, por ejemplo, examinar el término competencia en el artículo 1 del Convenio Europeo de Derechos Humanos, el cual reviste una importancia fundamental para la aplicación del convenio en situaciones complejas como las operaciones de paz en el exterior. El análisis doctrinal busca impactar directamente en las decisiones de las

61 J.H. von Kirchmann, Die Wertlosigkeit der Furisprudenz als Wissenschaft (ed. H.H. Meyer-Tscheppe, 1988), pp. 15, 29. [La traducción es nuestra].

62 Vid., en detalle Peters, "Die Zukunft der Völkerrechtswissenschaft: Wider den epistemischen Nationalismus", en 67 ZaöRV(2007), p. 721. 
cortes y en el proceso de elaboración de tratados. Tan está orientado por la práctica que ha sido llamado una "doctrina de la aplicación del derecho"63 y una "doctrina para preparar decisiones". ${ }^{64}$

Sin embargo, debido a ciertas características del derecho internacional, el análisis doctrinal en este aspecto tiene un valor limitado. Primero, la materia del derecho internacional es menos densa que aquélla existente en el principal campo de la aplicación doctrinal: contratos, responsabilidad civil y derecho de bienes. Existen, en total, menos reglas y decisiones judiciales. De manera tal, que un análisis semántico lógico de esta "ligera" materia es menos productivo.

En segundo lugar, una cantidad considerable del derecho internacional continúa sin codificación. El contenido exacto del derecho internacional consuetudinario debe primero ser investigado con métodos diferentes a los lógico-semánticos. Ésta es una tarea diferente de la investigación del significado o del sentido de una norma escrita (interpretación de los tratados). Fernand Tesón hace referencia a esta característica:

[...] no es posible identificar normas jurídicas internacionales mediante métodos doctrinales convencionales. Si la doctrina jurídica internacional pretende proponer valores humanos y no únicamente servir al poder, debe complementar la doctrina jurídica con una teoría de las relaciones internacionales y de la filosofía política. De otra manera, continuará siendo un ejercicio fútil. ${ }^{65}$

En tercer lugar, el derecho internacional es el resultado del compromiso político en un grado más elevado que el derecho nacional, y por esa razón es menos sistemático y menos claro que otras materias jurídicas. Estas tres peculiaridades del derecho internacional

63 "Rechtsanwendungswissenschaft": VAN AAKEN, "Funktionale Rechtswissenschaftstheorie für die gesamte Rechtswissenschaft", en M. JEsTAEDT y O. LePsius (eds.), Rechtswissenschaftstheorie (2008), p. 79.

64 "Entscheidungsvorbereitungswissenschaft": vON ARNAULD, supra nota 58, p. 87.

65 Tesón en Twining et al., supra nota 59, cita en p. 947. 
requieren dimensiones adicionales de investigación, aparte del análisis doctrinal del derecho.

\section{EMPÍRICA}

Una de las otras dimensiones se refiere a la investigación empírica. Aquí, la doctrina jurídica internacional pretende "estudiar las condiciones bajo las cuales el derecho internacional se forma y tiene efectos". ${ }^{66}$

El mismo Cassese utilizaba un método empírico, es decir, entrevistas con abogados eminentes, para descubrir algo "sobre el papel actual del derecho internacional en la comunidad mundial", así como descubrir cómo dichos abogados eminentes "habían resuelto este problema [del positivismo jurídico], y en particular hasta qué grado segregaron al derecho de otras ciencias sociales". ${ }^{67}$

La doctrina jurídica internacional empírica puede ser conducida tanto a macro o micro nivel. En cuanto al micro nivel, el investigador indaga sobre los orígenes de una norma particular. En el macro nivel, estudia trayectorias más significativas, por ejemplo, la evolución de regímenes jurídicos enteros, como el derecho del mar o el régimen del cambio climático. En cualquier caso, se preocupa de la investigación de factores concretos detrás del desarrollo de normas y la identificación de las condiciones bajo las cuales dichas normas funcionan.

La doctrina empírica también puede ser histórica. Por ejemplo, se puede investigar la evolución histórica del artículo 42 del Proyecto de Artículos sobre Responsabilidad Internacional de la Comisión de Derecho Internacional para probar una hipótesis sobre el desarrollo del concepto de obligaciones erga omnes (investigación

66 Shaffer y Ginsburg, "The Empirical Turn in International Legal Scholarship", en 106 AfIL (2012) 1, p. 1. [La traducción es nuestra].

67 Cassese, supra nota 4, prólogo, p.viiii. 
fundacional) o para aplicar esa disposición a un caso concreto de responsabilidad (investigación aplicada).

La investigación empírica se preocupa particularmente de los efectos del derecho internacional. En esta dimensión de la investigación, las normas son vistas como un modo de gobernanza y se investiga su cumplimiento. Este tipo de investigación explora el impacto del derecho internacional en las relaciones internacionales. Pretende establecer, cuándo, dónde y a qué grado estas normas dirigen el comportamiento de los actores relevantes, y se pregunta por qué y bajo qué circunstancias el derecho internacional se cumple o se quebranta. Dadas las dificultades de hacer cumplir el derecho internacional, esta dimensión es de particular importancia. Sin embargo, no funciona sin que se mire hacia las afueras de la disciplina. Puede beneficiarse de las teorías de nueva gobernanza en el derecho administrativo y la teoría administrativa. Más que cualquier otra cosa, debería aprovechar los resultados de la investigación paralela en las relaciones internacionales.

La investigación sobre el cumplimiento es investigación empírica, pero también está basada en la teoría debido a que funciona sobre modelos. Gregory Shaffer y Tom Ginsburg lo han llamado "el análisis emergente", es decir "análisis que oscila entre resultados empíricos, pruebas realizadas en el "mundo real”, y así subsecuentemente". ${ }^{68}$ Por ejemplo, Jack Goldsmith y Eric Posner utilizan un modelo de selección racional para estudiar el derecho internacional público, ${ }^{69}$ con normas jurídicas apoyadas en sanciones de manera similar a precios por cierto comportamiento. Para estos autores, la escasez de sanciones "duras" por violaciones al derecho internacional es el factor decisivo de las deficiencias en la operación del derecho internacional público. Hay, sin embargo, también mucho

\footnotetext{
68 Shaffer y Ginsburg, supra nota 66, p. 1.

69 J. L. Goldsmith y E. A. Posner, The Limits of International Law (2005).
} 
que puede ser ganado al trabajar con otros modelos en dicha investigación jurídica del "mundo real". ${ }^{70}$

\section{TEÓRICA}

Una tercera dimensión de la investigación es teórica. Lo que se quiere decir aquí son "teorías sobre el derecho" como lo estableció la Escuela de $\mathcal{N}$ ew Haven. ${ }^{71}$ Esto va más allá de métodos o las llamadas teorías usadas por quienes aplican el derecho para interpretar una norma jurídica en un caso específico, mas no para reducir su complejidad. El teórico del derecho se ocupa de cuestiones como ¿qué es el derecho internacional público? y ¿cómo funciona la argumentación del derecho internacional público? Las investigaciones de género sobre la estructura del derecho internacional y su sesgo en materia de género también recaen en esta dimensión. ${ }^{72}$ Buenas preguntas de investigación pueden hacerse en la dimensión teórica. Por ejemplo, las teorías sobre la creación de las normas consuetudinarias no han sido realmente satisfactorias hasta el momento. Ninguna de ellas ha sido capaz de explicar de una manera creíble la transición entre la violación de la norma antigua y el establecimiento de la nueva norma consuetudinaria. ${ }^{73} \mathrm{O}$, para dar otro ejemplo, dentro del escenario de la negación del derecho internacional ${ }^{74}$

70 H. Albert, Rechtswissenschaft als Realwissenschaft: das Recht als soziale Tatsache und die Aufgabe der Furisprudenz (1993), p. 7 y passim.

71 M. S. MaDougal, H. Lasswell, y M. Reisman, "Theories about International Law: Prologue to a Configurative Jurisprudence", en 8 Virginia 7 Int'l L (1968) 188, p. 200 (Faculty Scholarship Series, Paper 2577).

72 H. Charlesworth y C. Chinkin, The Boundaries of International Law: A Feminist Analysis (2000).

73 Vid., sobre la imposibilidad de distinguir el error jurídico (respecto de una norma consuetudinaria válida) de la nueva opinio juris KeLSEN, "Théorie du droit international coutumier", en 253 Revue internationale de la théorie du droit (1939), p. 263.

74 Bolton, "Is There Really 'Law' in International Affairs?", en 10 Transnat'l L and Contemporary Problems (2000), p. 1. 
parece particularmente importante llevar a cabo nuevas investigaciones sobre el carácter jurídico del mismo a pesar de su débil ejecutabilidad y legitimidad democrática.

En la dimensión de la investigación teórica están emergiendo una pluralidad de teorías. Hasta hace poco, el post-modernismo, en la expresión de los estudios jurídicos críticos (critical legal studies), ocupaba el espacio de la teoría. Presumiblemente, sin embargo, los estudios críticos se desplazarán a un segundo plano debido a que (por definición) no pueden ofrecer soluciones constructivas a los problemas. Otros enfoques podrán jugar un papel más importante, dependiendo del área del derecho internacional público, por ejemplo, los enfoques feministas en el derecho penal internacional y en materia de derechos humanos, o las teorías de la selección racional en el derecho de los tratados.

\section{4. ÉTICA}

Antonio Cassese era partidario de un enfoque ético del derecho internacional: "desde mi punto de vista, para que alguien sea un intelectual y no un abogado, debe otorgarle gran importancia a los valores éticos y debe tratar, de alguna manera, de utilizarlos". ${ }^{75} \mathrm{En}$ esa dimensión ética de la investigación, los académicos jurídicos internacionales deben investigar el contenido ético del derecho internacional (muchas veces arraigados en cosmovisiones específicas) y criticar éste en relación con estándares de justicia no-positivistas. ${ }^{76}$

Esta tarea de investigación les corresponde a los académicos jurídicos internacionales porque el derecho internacional público -como todo el derecho- alega ser justo. La evaluación del derecho positivo mediante la utilización de estándares no-positivistas de la justicia o mediante la equidad es incluso más adecuado en la

75 Cassese, supra nota 4, p. 142.

76 Vid., v. g., J. Rawls, The Law of Peoples (1999), quien considera "cómo el 'law of nations' puede ser desarrollado a partir de una idea liberal de la justicia” (p. 1). 
doctrina jurídica internacional que en el estudio del derecho nacional de los Estados democráticos. Ello se debe a que en el orden democrático, el derecho está justificado por su origen democrático y por los límites constitucionales del Estado. Las consideraciones de una legitimidad externa son problemáticas en relación con leyes que han sido adoptadas como resultado de un proceso democrático. Por el contrario, el derecho internacional público carece de un fundamento democrático directo. Las bases codificadas del derecho internacional público similares a aquéllas encontradas en las constituciones, que proporcionarían criterios para la evaluación de la legitimidad del derecho, son rudimentarias. Por esta razón, el estudio del derecho internacional público puede y debe incluir consideraciones éticas en mayor grado que la investigación del derecho nacional.

El derecho natural re-emergió brevemente después de la Segunda Guerra Mundial y en el derecho internacional público se asocia principalmente con Hersch Lauterpacht. Tras este breve renacimiento, la ética constructiva prácticamente se despejó de la materia. La intervención en Kosovo de 1999 representó un punto de partida. Inició un "regreso a la ética", como lo llamó Martti Koskenniemi, ${ }^{77}$ no únicamente en el discurso político y jurídico, sino también en el académico. Este "regreso a la ética" está documentado, para dar dos ejemplos, en la controversia sobre la responsabilidad de proteger y en el debate sobre la constitucionalización del derecho internacional.

En éstas y otras esferas de análisis, la dimensión ética complementa, de manera razonable, a otras áreas de investigación. Por ejemplo, la situación política actual sugiere una re-evaluación del principio de igualdad soberana y de la tensión entre la igualdad de jure de los Estados y la desigualdad de facto. Les corresponde a los académicos jurídicos internacionales no únicamente evaluar si está

77 Koskenniemi, “'The Lady Doth Protest Too Much', Kosovo, and the Turn to Ethics in International Law", en 65 MLR (2002), p. 159. 
emergiendo un principio general de desigualdad entre los Estados, pero también esbozar el impacto estructural de dicho cambio, así como sus implicaciones éticas. Otro proyecto de investigación dentro de la dimensión ética sería explicar la reformulación de la soberanía estatal como la responsabilidad frente a los seres humanos, misma que ya ha sido aceptada en la práctica estatal. Por supuesto que la visión del investigador influirá en su análisis de la pregunta si el propósito último de la soberanía estatal es la dignidad humana y los derechos individuales, pero mientras se argumente ex suppositione, el método continúa siendo académico.

Finalmente, la base moral de los derechos humanos es un aspecto apropiado para la doctrina jurídica internacional debido a que determina su interpretación, y por lo tanto, la aplicación y posibles limitaciones a dichos derechos. Por ejemplo, con la ayuda de investigadores éticos y empíricos sociales, los académicos jurídicos internacionales pueden identificar el consenso existente sobre los valores en relación con capacidades y necesidades humanas básicas. ${ }^{78}$

Éstos y otros problemas no pueden ser investigados adecuadamente si la dimensión ética se queda fuera. No se requiere únicamente la reintroducción de la dimensión ética de la investigación, sino también su reflejo en un meta-nivel, vis-à-vis el complejo triángulo de la pretensión de universalidad del derecho internacional público, la diversidad existente de las vidas y el ideal del pluralismo global.

\section{El ANÁlisis POSITIVO Y NORMATIVO}

Antonio Cassese deploraba la tendencia de la doctrina internacional europea de abstenerse de realizar una crítica a la práctica jurídica. Pensaba que los académicos estadounidenses, por ejem-

78 Cfr. A.K. Sen, Commodities and Capabilities (1985); Sen, "Capability and Wellbeing", en M.C. Nussbaum y A.K. Sen (ed), The Quality of Life (1993), pp. 30-66; M.C. Nussbaum, Women and Human Development: The Capabilities Approach (2000), pp. 4-15. 
plo, atacaban más seguido la postura del departamento de Estado. "Pero en nuestros países, tendemos a quedarnos callados. Es una característica desafortunada". ${ }^{79}$

Lo que Cassese propone es un análisis normativo del derecho internacional por parte de los académicos. En el supuesto ideal, el análisis normativo puede distinguirse de un análisis positivo, en el que el derecho es descrito, explicado y pronosticado. En realidad, existe una zona intermedia borrosa. Primero, porque la descripción ya es en sí misma una representación constructiva y sistémica, basada en numerosas distinciones y elecciones. El observador debe elegir los actores, los actos, los periodos de examinación, y debe interpretar textos. Durante todo esto, las preconcepciones (normativas) del observador, pre-estructuran su descripción positiva. Esta zona borrosa ha sido descrita adecuadamente por un académico jurídico-económico que insiste, en principio, en el análisis positivo del derecho: "la responsabilidad de los académicos es iluminar, y no promover sus propios ideales. Por otro lado, la buena doctrina resulta prometedora para la abogacía, pues puede clarificar relaciones causales que de lo contrario permanecerían oscuras. La iluminación no es neutral." $" 80$

El análisis del tipo ideal positivo puro (es decir, la identificación y descripción del derecho tal como es y de cómo se llevan a cabo su aplicación e interpretación) ha sido denominado negativamente como "un tipo de dogmatismo positivista", y como un "análisis seco y libre de valores de las normas internacionales". ${ }^{81}$ Desde esta perspectiva - misma que yo comparto-, la tarea de la doctrina internacional implica también un análisis normativo.

El análisis normativo significa la justificación o crítica de normas existentes y la realización de propuestas de reforma. Significa

79 Cassese, supra nota 4, p. 25.

80 J. P. Trachtman, The Economic Structure of International Law (2008), p. 4 (énfasis añadido). [La traducción es nuestra].

81 Tesón en Twining et al., supra nota 59, p. 942. 
también la evaluación de la aplicación del derecho y la crítica de dicha práctica. Debido a la libertad inherente de cualquier interpretación y aplicación de una norma a los hechos, cualquier evaluación de la práctica jurídica es, en el sentido de una teoría científica, un análisis "normativo" y no meramente "positivo". Dicho análisis normativo, por ejemplo, era llevado a cabo por académicos e instituciones académicas que analizaban la aplicación de las reglas sobre el uso de la fuerza y el Consejo de Seguridad por los gobiernos británico y estadounidense en 2003, quienes subrayaban que éstas habían sido malinterpretadas y distorsionadas por los actores políticos y no podían servir como una base jurídica adecuada para la invasión de Iraq en 2003. Dicho análisis normativo es rechazado por los positivistas jurídicos tradicionales, quienes alegan que la doctrina jurídica internacional debe únicamente ocupar un "papel [solo] como supernumerario y cronista". ${ }^{82}$ También es rechazada por neo-Kelsenianos contemporáneos, ${ }^{83}$ y por la escuela jurídica-económica extremista. Por ejemplo, Goldsmith y Posner consideran inaceptable que "teorizar en ocasiones alimenta, y es sobrepasado, por la especulación normativa de mejorar el derecho internacional". ${ }^{84}$

En contraste con esa postura, los siguientes párrafos buscan demostrar que las características específicas del derecho internacional, particularmente su apertura y su dinámica, requieren un análisis normativo del derecho y de sus aplicaciones.

82 Hillgruber, supra nota 31, especialmente p. 121.

83 Críticamente, sobre el poder legislativo equiparado de los académicos desde la perspectiva de una teoría pura del derecho, Vid., KAMMERHOFER, "Law-Making by Scholarship? The Dark Side of 21 st Century International Law 'Methodology", en J. Crawford y S. Nouwen (eds), Proceedings of the European Society of International Law 3 (2012), pp. 115-126.

84 Goldsmith y Posner, supra nota 69, p. 15. [La traducción es nuestra]. 
El derecho internacional está caracterizado por una indeterminación y vaguedad típica de las disposiciones de los tratados y por una gran cantidad de normas no escritas. Por lo tanto, más dudas se originan sobre la existencia de la lex lata que en el derecho nacional, el cual está codificado de manera relativamente completa y precisa en códigos, leyes y decretos. Además, el derecho internacional ha evolucionado gradualmente, en ocasiones de textos del soft law. El punto exacto del cambio entre una práctica pre-jurídica y una regla sólida de costumbre internacional difícilmente puede señalarse. Por estas razones, ni los cánones de la construcción de la interpretación de los tratados ni la investigación empírica sobre la formación del derecho consuetudinario proporcionarán en sí mismos resultados claros. Los resultados deben complementarse con consideraciones normativas. Por ejemplo, tiene sentido calificar una práctica y la opinio juris que la acompaña como suficientemente general y duradera cuando la norma jurídica identificada es conforme con el sistema jurídico internacional y está en armonía con otros principios jurídicos internacionales. Como lo estableció Antonio Cassese, "el positivista crítico debe sentirse libre[...] para evaluar críticamente la regla o la institución [...] a la luz de[...] los valores generales existentes en la comunidad internacional". ${ }^{85}$

Una segunda razón de lo atractivo del análisis normativo es la experiencia histórica de la indefensión de la doctrina "pura" del derecho internacional en relación con su modificación ideológica. Puede considerarse que el positivismo "puro" "involucra una prohi-

85 Vid., en este sentido Cassese, supra nota 4, p. 259. Cfr. Sobre una crítica de la negligencia de tomar en cuenta principios generales H. LAUTERPACHT, The Function of Law in the International Community (1933), p. 438: "el deseo de generaciones de abogados internacionales de restringir su actividad a un registro de la práctica de Estados ha desalentado cualquier intento de relacionar ésta con un principio jurídico superior o con la concepción del derecho internacional en su conjunto". [La traducción es nuestra]. 
bición o un impedimento de forma lógica y moral para los abogados en la lucha contra regímenes autoritarios". ${ }^{86}$ Notablemente, durante el Tercer Reich muchos académicos jurídicos internacionales de origen alemán no expresaron crítica alguna. En vez de señalar las violaciones al derecho internacional, se sumaron a una doctrina socialista nacional del derecho internacional mediante la cual las normas se modificaban y se adaptaban a la ideología. ${ }^{87}$

También en nuestro tiempo, el análisis puramente positivo ha engendrado una falsa seguridad. Debido a la apertura de las normas internacionales, muchas veces no es realmente claro cuál es su contenido. En esta situación, los Estados tenderán a alegar las reglas que les favorecen (y por lo tanto, a fijar su propia versión del derecho internacional) o harán lo que les plazca. ${ }^{88}$ Esta falsa seguridad llevará a un asesoramiento jurídico sin contenido y a recomendaciones inútiles sobre el cumplimiento de esas normas. Exactamente esto alimenta otro incumplimiento futuro del derecho internacional.

\section{El anÁlisis NORMATIVO CONDUCIDO PROPIAMENTE}

El análisis normativo que necesitamos no debe tomar la forma de intentos académicos de legislar. La autoridad (carente) de los académicos de hacer derecho fue explicada anteriormente en la sección IV. Un intento inconsciente de ganar autoridad se presenta cuando los académicos venden normas emergentes como derecho existente. Este fenómeno es común en la doctrina jurídica internacional, en gran medida porque la frontera entre derecho y lo que todavía no es derecho, debido a las características específicas del proceso jurídico internacional, no es clara. La denominación prematura de normas emergentes como derecho vigente es defectuosa en términos me-

86 Cassese, supra nota 4, prólogo, p.viii.

87 Vid., VAGTs, "International Law in the Third Reich", en 84 AfIL (1990) 661 y referencias.

88 Tesón en Twining et al., supra nota 59, pp. 942 y 945. 
todológicos porque mezcla (más allá de lo inevitable ${ }^{89}$ ) un análisis positivo con uno normativo, y porque deriva el "deber" del "ser". Adicionalmente, se corre el riesgo de socavar el poder normativo del derecho internacional en su conjunto. Cuando el académico jurídico afirma erróneamente la existencia de una norma jurídica, usurpa la posición del legislador sin justificación normativa. Está autorizado únicamente a proponer la reforma del derecho, y eso debe hacerlo por las razones anteriormente expuestas.

Mientras los académicos jurídicos señalen cuando hacen una evaluación (apoyados en principios del orden jurídico internacional), y señalen lo que, de acuerdo con su análisis, es lex lata, y lo que solicitan de lege ferenda, un análisis normativo se adecua completamente a los estándares académicos. En entrevista con Antonio Cassese, Louis Henkin describió la caminata en cuerda floja entre la reconstrucción metodológicamente correcta pero creativa del derecho y la juris-ficción poco académica como sigue:

No confío en aquéllos con buenas intenciones, no confío en aquéllos que dicen "esto es derecho porque debe de serlo". Pero apoyo a aquéllos, y soy una de aquéllos, que dicen "esto es lo que el derecho debería de ser, y mientras no estoy seguro que no lo es, déjenme averiguar hasta qué punto lo es o puede llegar a serlo". ${ }^{90}$

En esta manifestación (como una sistematización evaluativa y como clausura evaluativa de los huecos jurídicos) el análisis normativo no es únicamente un firme elemento de la doctrina jurídica internacional, en el sentido de que es "bueno tenerlo", sino que es una parte indispensable de ella. Por último, el análisis normativo es necesario, además del análisis positivo, precisamente por la gradualidad inherente del procedimiento jurídico internacional y debido a la indeterminación del derecho de los tratados, para prevenir violaciones al derecho internacional.

89 Vid. mi comentario supra en referencia a la nota 80.
90 Cassese, supra nota 4, p. 197. [La traducción es nuestra]. 
Sir Robert Jennings, en su entrevista con Cassese, expresó lo siguiente:

[L]a reforma del derecho es una materia muy, muy importante desde el punto de vista intelectual, y no nada más para los abogados $[\ldots]$ de alguna manera, estoy contradiciendo lo que dije al principio[...] que debes ser capaz de distinguir entre propuestas y lo que realmente es derecho y así subsecuentemente, casi como aténganse al derecho porque ése es su trabajo. Bueno, la vida está llena de contradicciones y ambivalencias [...] las ambivalencias llevan a la verdad. Con dos ideas contradictorias, puedes encontrar que ninguna representa la verdad, pero que algo que involucra a ambas y que es parte de ambas es en algún modo una aproximación mayor a la verdad. ${ }^{91}$

En resumen, la ambivalencia entre el análisis normativo y el análisis positivo es lo que caracteriza la doctrina jurídica internacional. Contiene una tensión productiva.

\section{x. Conclusión}

Aunque apenas conocí personalmente a Antonio Cassese, se ha convertido en uno de mis héroes, precisamente porque sus textos académicos nunca me parecieron un Glasperlenspiel. Todo lo que leí de él (solo una fracción de su amplísima obra) me pareció inspirado por un gran humanismo. Claramente, estaba inclinado hacia una agenda política, pero el rigor del argumento generalmente no se veía afectado por ello. Para mí, el enfoque de Cassese es la mejor demostración de que cualquier separación estricta entre derecho y política no es ni factible ni deseable. Los textos jurídicos de Cassese son profundamente políticos, pero no significa que por esto sean poco académicos. Admiro a Cassese no porque apruebe su agenda política (aunque ése sea el caso), pero porque me enseñó cómo entretejerla con el razonamiento jurídico.

91 Jennings, en ibid., p. 143. [La traducción es nuestra]. 
La conclusión de Antonio Cassese en Five Masters es:

[S] encillamente, la clave de los principales problemas de la comunidad internacional está en las manos de los políticos, diplomáticos y líderes militares. Sin importar lo anterior, los académicos jurídicos pueden sugerir ideas y proponer soluciones, sin embargo, sin hacerse muchas ilusiones. ${ }^{92}$

Éste es el curso de una "utopía realista" en contraste con una "utopía ilusoria” y es expresamente el territorio de los académicos jurídicos. 